\title{
Hacia una organización textual de los manuscritos del Chronicon
} mundi de Lucas de Túy

Emma Falque

\section{Citer ce document / Cite this document :}

Falque Emma. Hacia una organización textual de los manuscritos del Chronicon mundi de Lucas de Túy. In: Cahiers de linguistique hispanique médiévale. №23, 2000. pp. 87-99.

doi : $10.3406 /$ cehm.2000.915

http://www.persee.fr/doc/cehm_0396-9045_2000_num_23_1_915

Document généré le 15/10/2015 


\section{HACIA UNA ORGANIZACIÓN TEXTUAL DE LOS MANUSGRITOS DEL CHRONICON MUNDI DE LUGAS DE TÚY}

\section{Introducción}

A la amable invitación que recibí para participar en este coloquio he querido corresponder con una contribución sobre una de las obras del autor que más me atrae y en el que estoy trabajando en este momento, Don Lucas, quien, como saben todos ustedes, fue primero canónigo de San Isidoro en León y posteriormente obispo de Túy. De este autor he elegido la que es quizás su obra más representativa, el Chronicon mundi, su gran aportación a la historiografia medieval hispana. Mi intención es ofrecer una visión de conjunto, desde un punto de vista fundamentalmente filológico, de la transmisión manuscrita del Chronicon mundi de Lucas de Túy.

He de señalar que éste es mi objetivo inmediato, el estudio de la transmisión manuscrita, pero que éste -como en otros casos en los que he trabajado, la Historia Compostelana o la Historia Rodericiconstituye un paso previo para editar el texto. Mi propósito como filóloga consiste en ofrecer a los medievalistas y estudiosos de la historiografia hispana la edición crítica del Chronicon mundi del Tudense, que aparecerá, como las anteriores en el Corpus Christianorum.

Se trata de una edición que se ha hecho esperar, pues la única de que disponemos es la del P. Mariana publicada por A. Schott en el tomo IV de su Hispania Illustrata (Frankfurt, 1608). Cirot trató a principios de nuestro siglo $^{1}$, sin conseguirlo, de publicar una

1) G. Cirot, Mariana historien (Bibliothèque de la Fondation Thiers, VIII. Ftudes sur l'historiographie espagnole), Paris, 1905, p. 75. 
nueva edición de esta obra. También por entonces Don Julio Puyol, miembro de la Real Academia de la Historia, publicó un trabajo que pretendia ofrecer algunos datos previos para la edición del Chronicon mundi ${ }^{2}$, que la Academia consideraba de gran interés porque habia sido una de las fuentes principales de que se sirvieron los compiladores de la Crónica General ${ }^{3}$. Es el suyo el único trabajo publicado -aun con muchas deficiencias y una información muy escueta- sobre el conjunto de la transmisión manuscrita de la obra, cuyos datos se complementan con los que nos ofrece el valiosísimo Index... del Prof. Díaz y Díaz ${ }^{4}$ con noticias precisas de las signaturas y localización de los diferentes manuscritos, y con los catálogos de algunas bibliotecas. Lo demás son referencias 0 descripciones parciales y citas indirectas.

Curiosamente en la actualidad el Chronicon mundi de Lucas de Túy parece estar suscitando un mayor interés, en comparación con lo ocurrido en los últimos cuatro siglos. El Prof. Vázquez de Parga emprendió la tarea de una nueva edición aunque, no llegó a publicarla. Con él intenté colaborar hace ya algún tiempo; pero fue una colaboración que -desgraciadamente- resultó imposible, por lo que, como no me faltan tenacidad y entusiasmo, me di a la tarea de realizar sola la edición crítica del Chronicon mundi para el Corpus Christianorum. Estando las cosas asi, se ha presentado recientemente en Salamanca una tesis sobre el Tudense dirigida por la Prof. Codoñer, que no he podido consultar. A todo ello hay que añadir el interés por Lucas de Túy y su obra de los profesores Peter Linehan, de la Universidad de Cambridge, y Georges Martin, de la Universidad París 13. También trabaja desde hace algún tiempo sobre Lucas de Túy mi colega Patrick Henriet, con el que espero poder colaborar en la publicación de la otras obras del Tudense: el De altera vita y el $D e$ Miraculis.

2) J. Puyol, "Antecedentes para una nucva edición de la crónica de Don Lucas de Túy", BRAH, 69 (1916), pp. 21-32.

3) J. Puyol, art. cit., p. 21.

4) M.C. Diaz y Diaz, Index Scriptonum Iatinorum Medii Aevï Hispanorum, Salamanca, 1958, núm. 1226, p. 263. A la relación de manuscritos ofrecida por el Prof. Díaz y Diaz habria que añadir un segundo manuscrito del Chronicon, que se encuentra tambićn en la que fuc Biblioteca Capitular y Colombina de Scvilla y es cn la actualidad Institución Colombina (56-4-43. Sign. antigua AA 141-63 y posteriormente 82-3-47) y, por otra parte, eliminar de csta relación el ms. de la Biblioteca Nacional de Lisboa 353, que, simplemente y según me indicaron desde alli, no corresponde a Lucas de Túy. Son, por tanto, diecisietc los manuscritos conservados que nos han transmitido el Chronicon mundi. 


\section{La edición del texto}

Tras esta necesaria introducción paso ya a exponer los prolegomena a esta edición -es decir, la transmisión manuscrita de la obra- que son, en cierto sentido, los entresijos, el andamiaje sobre el que espero construir la edición crítica del Chronicon mundi.

Contaba Don Pío Baroja en sus Memorias que no creía que su biografia pudiera tener algún atractivo, en comparación con el que sus lectores podían encontrar en los argumentos de sus novelas, sensación que muchos filólogos compartimos con el novelista, pues consideramos que lo único que interesa al público es la novela que escribimos -o mejor, que se nos escribe-, en nuestro caso el texto que ofrecemos, la edición, y que la relación que mantienen los manuscritos que nos permite proponer la hipótesis de un arquetipo, poco tiene de atractivo, por más que sea indudable su utilidad. Sin embargo, muchas veces es una auténtica novela policíaca el llegar a establecer las relaciones entre los diferentes manuscritos que nos han transmitido un texto y esta investigación que debe llevar a cabo el filólogo, puede tener una larga historia.

La narración de las relaciones textuales entre los manuscritos que se nos conservan del Chronicon mundi de Don Lucas, es tan simple como establecer la existencia de dos ramas claras más una serie de testimonios que de momento me llevan a prever la posibilidad de una tercera rama. Como verán, tiene muy poco misterio establecer que el manuscrito más antiguo de Salamanca $(S)$ da origen a una familia $(S S V F)$ y que otro de los manuscritos más antiguos, el que estuvo en Toledo $(T)$, es el punto de partida de otra familia (TPLFK), dejando al margen el códice del s. XIII conservado en León $(h)$ y al resto cuya relación parece, en principio, más obscura. Si esto parece bastante simple y carece de misterio, las cosas cambian si intentamos establecer las relaciones de los códices de una misma familia, las relaciones de los restantes manuscritos que constituyen - al menos algunos- una tercera rama y las de todos ellos entre sí. La niebla se hace más densa a medida que nos acercamos al arquetipo.

Esta organización es la normal en cualquier trabajo filológico neolachmanniano, es decir, en cualquier trabajo que confie en que, con todos sus problemas, los sucesivos errores, omisiones, transposiciones, etc., permiten establecer una relación fiable entre los testimonios que se nos conservan de una determinada obra, con matizaciones que no es necesario hacer ahora aquí, pero que 
cualquiera entenderá sólo con que se plantee el modo diferente de transmisión textual que tiene un poema de Jorge Guillén, un artículo de Mariano José de Larra, alterado por la censura, o un texto científico sobre las propiedades de la aspirina. Cualquiera que se acerque al Chronicon mundi, la gran aportación historiográfica de Lucas de Túy, puede comprobar que nos encontramos ante una obra que comparte las características de un texto histórico, de un texto literario y un texto científico.

\section{El triple carácter histórico, científico y literario del texto}

El carácter histórico de esta obra del Tudense parece, en principio, evidente. Deudora de la Crónica de Isidoro en primer lugar, constituye también una fuente indiscutible para los acontecimientos que le son más cercanos al autor. La obra comienza por los orígenes del mundo para terminar con acontecimientos de su tiempo, llegando hasta 1236, fecha de la conquista de Córdoba por Fernando III. A pesar de la falta de sentido crítico que lo lleva con frecuencia a aceptar versiones fantásticas de los hechos, es importante desde un punto de vista histórico pues pone fin a un largo silencio historiográfico, abierto tras la Chronica Adefonsi Imperatoris a mediados del siglo anterior.

Pero el Chronicon mundi pretende ser también un texto científico, escrito en latín, que ofrecía en su día un compendio de Historia Universal, los conocimientos básicos de Historia Sagrada, Historia de Egipto, de Grecia, de Roma..., con algún anacronismo e inexactitudes, como el conocidísimo pasaje en el que se le atribuye a Aristóteles la nacionalidad hispana ${ }^{5}$. Y, por supuesto, es también un texto literario. La narración de algunos acontecimientos nos acerca a otros géneros como el hagiográfico. Recordemos, por ejemplo, la irrupción de Santiago en la batalla de Clavijo en su caballo blanco, para siempre asociado en la iconografia al Apóstol, o el relato del descubrimiento milagroso de los restos de San Isidoro en Sevilla y su posterior traslado a León.

5) Para una interpretación de semcjante dislate, cf. F. Rico, "Aristotelcs hispanus: en torno a Gil de Zamora, Petrarca y Juan de Mena", Italia medivevale e umanistica, 10 (1967), pp. 143-164. 


\section{La historia de la transmisión del texto}

A quien, como yo, entiende que una organización textual tradicional es la mejor manera con que contamos de poder llegar a esa hipótesis que es una edición crítica, no puede pasarle desapercibido el trabajo innovador de Bernard Cerquiglini, Elogio de la variante, que - al margen de la admiración que por él sienten los "nuevos filólogos" o del rechazo que demuestran otros- ha tenido la virtud de llamar la atención de quienes a veces nos perdemos por el bosque de los stemmata sin que sus ramas nos dejen ver que la transmisión textual no puede reducirse exclusivamente al error, pues no es ajena al placer de la creación. Un novelista como Leonardo Sciascia nos lo ha sabido mostrar cuando describe a un copista que se recrea copiando un manuscrito :

"Para empezar había separado el códice folio por folio. Luego, con especial cuidado, había entremezclado la pila de hojas, como si se tratara de un mazo de cartas para algún juego; porque el suyo era, sin duda, un juego de gran habilidad, [...] Después con paciencia, con mucha calma, había vuelto a unir los folios del códice. [...] Fray Giuseppe Vella enriquecía, pues, el códice con palotes ligeros y vibrátiles como patas de mosca, con puntos diminutos, tildes y cedillas, que distribuía con atención especial y con mano firme." 6 .

El placer del copista no es menor que el que experimenta el filólogo cuando se enfrenta con un códice que nos transmitc un texto. A este respecto voy a referirme rápidamente a tres hechos en los que un filólogo, en una organización textual tan simple o tan mecánica como la presente, encuentra aspectos que pueden ser de interés.

Por ello, si, como hemos dicho, esta obra del Tudense es un texto histórico y, como tal, está sujeto a posibles censuras o distintas formas de intervención ideológica, quizás no fuera casual que se escribiera en "la pujante España de los principios del s. XIII" -en palabras de F. Rico ${ }^{7}$ y se copiara al menos en tres ocasiones en el s. XIII esta obra del Tudense, que incluye una Laus Hispaniae ${ }^{8}$. Me refiero a los códices más antiguos de toda la transmisión

6) L. Sciascia, El Archivo de Fgipto, Barcclona, 1984, pp. 26-27.

7) F. Rico, art. cit., p. 144.

8) Con distintos títulos en los mss. para este segundo prólogo: Eiusdem Lucac de excellentia Hispaniae ITPFK, Alius prologus de felicitatibus Yspaniac $M$, Incipit $2^{\circ}$ prologus $\mathrm{D}$. Lucac Tudensis $G$, tútulo que otros omiten. 
manuscrita: el de Salamanca ( $S$, ms. 2248), el que estuvo en Toledo $(T ; B N 10.442)$ y el que se conserva en la Real Colegiata de San Isidoro de León ( $I$; ms. 20). Si tenemos en cuenta que el Chronicon hubo de ser escrito poco después de 1236, fecha de la conquista de Córdoba, no deja de ser llamativo que se conserven tres códices del s. XIII entre los que nos han transmitido la obra.

A este respecto es razonable también que nos preguntemos por qué lleva a cabo su edición Mariana y el transfondo ideológico que puede haber en ello. La pregunta que cualquier filólogo se hace, sin pretensión de llegar a una solución total, es el por qué desde la edición de Mariana se ha desatendido una obra que tiene algún interés historiográfico. La primera respuesta sería acorde con nuestro tradicional victimismo, amparándonos en la secular desidia capaz de desatender a nuestras propias tradiciones, explicación que, por el simple hecho de acercarse demasiado a otras que se apoyan en esa etérea alma de los pueblos, ustedes me aceptarán, debe ser sin más desechada.

Me aceptarán igualmente, espero, sobre todo quienes se hayan adentrado más en el campo de la filología, que no resulta tampoco creíble una explicación basada en la pequeñísima conservación de ejemplares de la edición de Mariana ${ }^{9}$, pues tampoco eran muchos los manuscritos que pudo allcgar Petrarca para reconstruir el texto de las Décadas de Tito Livio, y si el poeta florentino se empeñó en leerlo entero es porque en este terreno es evidente que nadie nos puede asegurar el paso de la cantidad a la calidad; del mismo modo el Diálogo de la lengua de Valdés se sustenta en una única copia, motivo que no disuadió a Mayans en el XVIII de editarlo. Este criterio mecanicista de pequeño número de ejemplares sirve de poco para explicar que en el gran momento histórico de la edición de textos, que supuso el s. XVIII, no se encontraran pretextos suficientes para volver la mirada a este texto editado por Mariana, que podía reforzar las ideas de los ilustrados sobre el pasado de España.

\subsection{Supresiones $y$ adiciones}

Tenemos que tener presente, por otro lado, que en la transmisión del Chronicon mundi hay hechos que recuerdan lo propio de los textos científicos, en los que es frecuente encontrar supresiones

9) Pocos ejemplares de la edición de Mariana, publicada por Schott, se hallan en las bibliotecas de nucstro pais. Ésta podria haber sido la causa de que nadic hubicra acometido la labor de realizar otra edición del Chronicon mundi, en opinión de L. Vázquez de Parga quien emprendió la tarea, aunque desgraciadamente no llegó a publicarla. 
o adiciones, etc. Recordemos, por ejemplo, la transmisión de los textos de medicina desde la Antigüedad hasta la Edad Media ${ }^{10}$, en los que normalmente se añaden datos o se suprimen, para poner al día la doctrina científica. No faltan casos de adiciones o supresiones en esta obra; recordemos las largas omisiones de $S$, párrafos enteros, que nos han servido para establecer la familia de manuscritos derivados de $S$. Una de ellas nos narra la anécdota de la invención del vidrio irrompible, que el Tudense sitúa en época de Tiberio y que encontramos también en el Satiricón (Sat. 51) y posteriormente en las Etimologias de San Isidoro (XVI 16, 6):

Cuius tempore Lucillus quidam excogitauit... auri et argenti uilesceret pretium] om. $S s V F$ (p. 31, 18-25).

Cuestión aparte es si este fragmento está o no desplazado de lugar, pues si lo omitimos, como $S$, el texto sigue teniendo todo su sentido: nos narra la crucifixión del Señor ${ }^{11}$.

Con relación a estas omisiones y adiciones de los diferentes manuscritos, parece oportuno recordar que cualquier obra medieval pudo haber sido retocada o revisada por un continuador. A menudo los copistas no fueron muy respetuosos con los textos, en especial con los textos en lengua vulgar ${ }^{12}$, y, por otra parte, según he señalado en otro lugarl3, "no podemos acercarnos a la autoría de una obra medicval con los esquemas mentales que pueden ser válidos para estudiar una obra moderna. [...] La propia transmisión de los textos medievales mediante manuscritos en los que pueden intervenir de manera decisiva los copistas, hace más dificil aún la tarea de dilucidar si una obra medieval puede atribuirse exclusivamente a la redacción de un único autor".

\subsection{La contaminación}

Hay un hecho más que, sin ser exclusivo de los textos literarios, tiene en ellos un lugar privilegiado: la actuación del copista como

10) Sobre la transmisión de los textos médicos, véase M.E. Vázquez Buján (ed.), Tradición e innovación de la Medicina Latina de la Antigüedad y de la Alta Edad Media, Santiago de Compostela, 1994.

11) Cito la cdición de Mariana omitiendo el párrafo referente al vidrio, que suprime $S$ : Anno vero Tiberii oclauo decimo dominus crucifixus est peractis a principio mundi annis quinque mille ducentis triginta duobus. In multis aukem Iudaeis accusantibus Pilatum apud Trberium, Pilatus in exilium missus est Iugdunum, unde erat oriundus...

12) Véasc A. Blecua, Manual de crílica lextual, Madrid, 1983, pp. 163 y ss.

13) En relación con la Historia Roderici, cf. E. Falque- J. Gil- A. Maya, Chronica hispana saeculi XII (CC.CM LXXIA), Turnhout, 1990, pp. 20-21. 
filólogo, responsabilizándose de la elección o corrección textual. Normalmente la filología toma como un mal menor al que hay que resignarse, la contaminación textual. No hay que explicar que visto este hecho -la contaminatio- como una enfermedad, con lo que el filólogo se topa es con sus secuelas; lo que, dicho de otra forma, supone que podamos descolocarnos ante una lectura inexplicable dentro de una rama porque no tenemos modo de saber si tal lectura se debe a que un copista ha acudido a otro texto para resolver una duda. En nuestro caso es una apasionante aventura la que supone adentrarse por este ámbito de la contaminación en ejemplos tan claros -me refiero al Chronicon mundi- como los siguientes:

El primero es el caso de $F$, que presenta una relación con el resto peculiar, pues además de derivar de uno, conoce y coteja en ocasiones otro. En los márgenes encontramos alusiones a un recentior codex, es decir hay una contaminatio. Si tenemos en cuenta algunos pasajes $F$ parece derivar de $V$, de quien recoge en ocasiones variantes y alguna omisión, como estas del prólogo:

uerum Deum] Deum uerum VF

negotio sanguine] sanguine gottico $V F$ (gotico $F$ )

seruatur] sumatur $V F$

rebus] regibus $V F$

serico] seritur $V F$

agilitate] agentilitate $V F$

carnis] carius $V$, charius $F$

quia sicut hec stella in occiduo climate fulget inter sidera sic Yspania om. $V F$ (en $F$ está añadido entre líneas).

$\mathrm{Y}$, por otra parte, el recentior codex, al que se refiere $F$ bien puede ser $E$, el otro manuscrito conservado en El Escorial. Por ejemplo, en el prólogo alude $F$ a otra lectura del recens codex, que es una variante de $E$ :

peruolat] $F$ (ad marg: recens codex euolat), euolat $E$

Cuando $V$ recoge las largas omisiones de $S$, del que deriva, $F$ acude a este códice del Escorial, al que he llamado $E$, para subsanarlas, incluyendo las variantes -alguna no meramente gráfica- de $E$. Por ejemplo, así ocurre en la omisión de eo quod Tiberius... uniuerso orbi (p. 31, 42-51):

importuni senis] om. SsVF (in $F$ importuni senis ad marg. addito), in portum sedis $I T$, importum sedis $P$, importuni senis $E$ 
$\mathrm{El}$ otro ejemplo de contaminación es el de $G$, perteneciente al subgrupo $M A C E G H$, que copia de un códice, que podría ser el más antiguo de este grupo, es decir, $M$, pero una mano posterior al margen corrige en ocasiones teniendo a la vista otro de una familia diferente, que quizás fuera $V$. Así lo demostrarían un par de ejemplos del prólogo:

carnis] carius $V$, carnis in charius ad marg. man. recent. correcto $G$ ubique Christi ecclesia] usque quaque in Christi ecclesia $V$, ubique Christi ecclesia (ubique in usquequaque ad marg. man. recent. correcto) $G$

Estos dos ejemplos de contaminación en la transmisión textual del Chronicon mundi, que quizás no sean los únicos, nos recuerdan que esta obra es, también, un texto literario y que tenemos que tener en cuenta siempre todos los factores que se suman -y no es el menos importante la intervención de los copistas- para ofrecernos un texto.

\subsection{La peculiaridad del códice I}

Partiendo de estos presupuestos y adentrándonos por este camino hacia el stemma codicum por el que les voy conduciendo, lo seguro es la existencia de dos familias: la del manuscrito más antiguo de Salamanca $(S s V F)$ y la de otro de los manuscritos más antiguos, el que estuvo en Toledo (TPLFK), dejando al margen el códice del s. XIII conservado en León $(I)$.

Éste último, además de algunos errores y omisiones, transposiciones de palabras, etc., presenta una peculiaridad por la que se opone de manera clara al resto de los manuscritos del Chronicon: el relato que nos ha transmitido de la Translatio sancti Isidori, peculiaridad que he estudiado hace poco en un artículo presentado para el Homenaje al Prof. García y García ${ }^{14}$. Según la versión transmitida por $I$, los obispos de León y Astorga habrían ido en realidad a buscar el cuerpo de San Isidoro, que, milagrosamente hallado, trasladarian a la capital leonesa para ser depositado solemnemente allí. El manuscrito da la impresión de haber sido retocado o corregido. La corrección estaria hecha con sumo cuidado; de hecho, en las fotocopias de $I$, esta corrección casi no se percibe, aunque sí parece haber sido corregido, cuando se lee el códice in situ.

14) E. Falque, "La Translatio s. Isidori en el Chronicon mundi de Lucas de Túy", Studia Gratiana (en prensa). 
Desde un punto de vista de crítica textual esta particularidad de $I$, frente a todo el conjunto de la tradición manuscrita de la obra, permite afirmar que de este códice no deriva ningún otro de los manuscritos conservados, $\mathrm{o}$, al menos, que ninguno fue copiado después de que éste fuera corregido para ofrecernos una narración radicalmente distinta del traslado de los restos de San Isidoro ${ }^{15}$.

\subsection{Las familias $S, T$}

Las dos familias de $S$ y de $T$ pueden establecerse bien a partir de errores y omisiones. Además de otras menos extensas a lo largo de la obra, encontramos tres párrafos que $S$ omite en la primera parte, en la Chronica b. Isidori, que nos pueden servir para establecer la familia de mss. derivados de $S$. Estos tres pasajes, que se encuentran próximos, son los siguientes: 18-25).

a. Cuius tempore Lucillus... uilesceret precium om. SsVF (p. 31 ,

b. Fuit isdem temporibus... et genus om. SsVF (p. 31, 31-37).

c. eo quod Tiberius... uniuerso orbi om. SsVF (p. 31, 42-51).

Como ya he dicho anteriormente, al hablar de los casos de contaminación de este grupo de manuscritos, $F$ presenta una relación con el resto peculiar, pues además de derivar de uno conoce y coteja en ocasiones otro, ya que en los márgenes encontramos alusiones a un recentior codex.

En cuanto a la familia de $\mathcal{T}(T P L F K)$, esta relación puede demostrarse si tenemos en cuenta los errores contenidos en ellos. Al estudiar el Chronicon mundi, que al ser una obra extensa nos ofrece suficientes datos, me he centrado en las omisiones de $T$, que son bastante frecuentes, a pesar de tratarse de un códice copiado -al menos aparentemente- con esmero. Todas estas omisiones están recogidas por $P L \mathcal{J} K$. No es mi propósito ofrecer aquí una lista exhaustiva de omisiones de $\mathcal{T}$ que se repiten siempre en $P L J K$, ofrezco sólo algunos ejemplos, los necesarios para establecer la familia de manuscritos de $T$. Hay que hacer la salvedad por una parte de que $\mathcal{J}$ es un manuscrito que resume en ocasiones, como veremos más adelante, por lo que a veces no podemos constatar las omisiones de $T$ y, por otra, de que $K$ recoge las omisiones de $T$,

15) Para el texto de $I$ y las razones que pudo haber para que cste manuscrito del XIII, conservado en la Real Colcgiata de San Isidoro de León, de donde parece no haber salido, cambiara por completo la narración del Chronicon mundi dando otra vcrsión del traslado del cuerpo de San Isidoro desde Sevilla, véase el trabajo anteriormente citado. 
pero la mayor parte de las veces otra mano añade al margen lo que omite $T$.

Las encontramos ya en la primera parte, la versión de la Chronica de Isidoro que incluye nuestro Chronicon:

et extensi flatu aure percussi tenuem sibilum reddebant om.TPLFK (p. 12)

Augustum et Antonium om.TPL (p. 24)

Regnumque est concessum Yrcano om.TPLK (p. 26)

post mortem Leouegildi om.TPLJK (p. 38)

Las omisiones de $T$, recogidas fielmente por $P L$, vuelven a repetirse en la Historia Vandalorum y Gotorum:

regno Gallias irrumpunt Francos prosternunt. Directoque om.TPLJK (p. 40)

Y así llegamos a las últimas páginas de esta obra, al libro IV del Chronicon mundi. Se repiten, de nuevo, las mismas omisiones en TPLK:

sed cum reuersi a sancto Iacobo imperator et rex Lodoicous uenirent om. TPLK (p. 105)

Adefonsum sed iste rex Portugalie om.TPLK (p. 106)

cum innumerabili suorum exercitu om. TPLK (p. 106)

Ya he hecho referencia a la peculiaridad de $\mathcal{F}$, que resume en ocasiones el texto. Ofrezco un caso a modo de ejemplo: En el fol. 185r salta desde ...postea genuerit., que corresponde a la pág. 28 de la edición de Mariana, a Herodes se illusum ab eis..., de la pág. 29, sin hacer ningún tipo de aclaración. Quizás estos saltos en la copia del manuscrito se puedan explicar por una nota que hay en el fol. 179r. que dice: "quando llegamos a escribir esta plana faltonos el compañero que nos ayudaba". A partir de aquí al copista parecen fallarle las fuerzas, pues siempre es más llevadero el trabajo en colaboración; de aquí que nuestro copista, incapaz de acometer en solitario la tarea, pudiera darse a resumir un texto que se le antojaría demasiado largo.

\subsection{Un grupo especial de manuscritos}

Para concluir esta visión de conjunto, que he querido ofrecer, de la transmisión manuscrita del Chronicon mundi de Lucas de Túy, he de referirme también a los testimonios que no pertenecen a estas 
dos familias, dejando a un lado el códice de León $(I)$ del que no deriva, como hemos visto, ninguno de los conservados en la actualidad. Se trata de los manuscritos a los que he denominado $M A C E G H$, que quizás tengan alguna relación entre sí pero cuyo parentesco, en el momento en que me encuentro en mi investigación, no puedo definir con claridad.

Todos tienen en común el título que hay delante del prólogo del Chronicon: Incipit prologus de primis libris cronicorum (chron-E) beati Ysidori (Isidor-EG) Yspaniarum (Hysp- $A$, Hisp- $C G$ ) doctoris archiepiscopi Yspalensis (Hisp-ACG), MACEGH, oponiéndose a unos que no tienen título alguno como $S_{s} V$ y a otros que nos han transmitido otro título diferente: Lucae diaconi praefatio in historiam seu chronicam beati Isidori archiepiscopi Hispalensis (...Hispalensis archiepiscopi $T$ ) IT.

De este grupo de manuscritos el más antiguo es $M$, fechado por unos en el XIV y por otros en el XV. Los demás, es decir, $A C E G H$, son de los siglos XV y XVI y quizás dependan directa o indirectamente de aquél. A éstos habría que añadir el de la Colombina de Sevilla del s. XVII, que contiene sólo los libros III y IV del Chronicon ( $h$ ) y que posiblemente dependa del otro manuscrito conservado también en la Colombina $(H)^{16}$.

\section{Colofón}

He pretendido dar cuenta a ustedes de los pasos previos que estoy dando para ofrecer una edición del Chronicon mundi. Estos pasos no están exentos ni de placer ni de preocupación. Son los propios de una aventura por los caminos de la filología, en los que si hasta hace pocos días he creído que existía un nuevo códice en Barcelona, con el que debía contar, hoy sé por la diligencia y profesionalidad de una bibliotecaria, Doña Anna Gudayol que tal códice no existe -es sólo una referencia de un inventario de la biblioteca de trabajo establecida por el Papa Luna ${ }^{17}$ en el castillo

16) Cf. E. Falque, "Lucas de Túy en Sevilla", Arqueólogos, historiadores y filologos. Homenaje a Fernando Gascó, Kolaios, 4 (1995), pp. 765-771.

17) El texto de dicho inventario, que lleva como fecha de inicio el 30 de junio de 1423 , ha sido editado recientemente por $\mathbf{H}$. Jullien de Pommerol - J. Monfrin, La bibliotheque pontifucale à Avignon et Peñiscola pendant le grand schisme d'Occident et sa dispersion. Inventaires et concordances, Roma, 1991, 2 vols. y por J. Perarnau, "Els inventaris de la biblioteca papal de Peñíscola a la mort de Benet XIII", Arxiu de Textos catalans Antics, 6 (1987), pp. 11-14; 185-226. 
de Peñíscola-, pero sí parece que otro asoma en el horizonte: el ms. 1003 de la Biblioteca de Catalunya, que aún no he podido consultar ${ }^{18}$. Es de este apasionante trabajo -no bien reflejado en los stemmata que construimos los filólogos- de lo que he querido hablarles.

La realidad se nos hace adversa no pocas veces hasta poner en peligro esto que he presentado aquí. Esa realidad ha ido retrasando la edición crítica de esta obra, que, Deo uolente, confio llevar a buen puerto en el próximo año de gracia de 1999, en el que espero poder repetir lo que Mariana escribía a los hermanos Schott cuando envió su obra para la publicación: "ya los libros de Don Lucas se encaminaron a Flandes" 19 .

\section{Emma Falque Universidad de Sevilla}

\section{SIGLA}

Códices

S Salmanticensis BU 2248 s. XIII

I Lcgionensis Rcal Colcgiata de San Isidoro 20 s. XIII

T Matritcnsis BN 10442 (olim Tolctanus 27-28) s. XIII

B Barcinonensis BC 1003 s. XIII/XIV

M Matritensis BN 4338 (P.138) s. XIV

P Pcrizonius. Lciden BU F.9 s. XIV

s Salmanticensis BU 203 s. XIV (tantum librum I continens)

L Lcgionensis Real Colegiata de San Isidoro 41 s. XV

V Vaticanus Vat.lat. 7004 s. XV

A Matritensis BN 1534 (F.130) s. XV

C Matritensis BRAH G-2 s. XV

E Escorialensis f.I.18 s. XVI

F Escorialensis b.I.9 s. XVI

G Salmanticensis BU 1791 (olim Matritensis B Pal. 2C3) s. XVI

H Hispalensis B Colombina 58-1-2 (olim 83-6-AA) s. XVI

J Matritensis BN 898 s. XVI

K Matritensis BRAH 11-2-50 s. XVII

h Hispalensis B Colombina 56-4-43 (olim 82-3-47) s. XVII (tantum libros III-IV continens)

18) Poco despućs de cste coloquio cclebrado en París pude colacionar cl manuscrito 1003 de la Bibliotcca de Catalunya (B Barcinonensis s. XIII/XIV) sobre cl que presenté una comunicación en XIII Simposi d'Estudis Clàssics. Secció Calalana de la SEEC celcbrado en Tortosa cn abril de 1998 (en prensa).

19) Como decia en una carta, enviada el 8 de noviembre de 1605, a Dávila, cf. G. Cirot, op. cut., p. 74. 